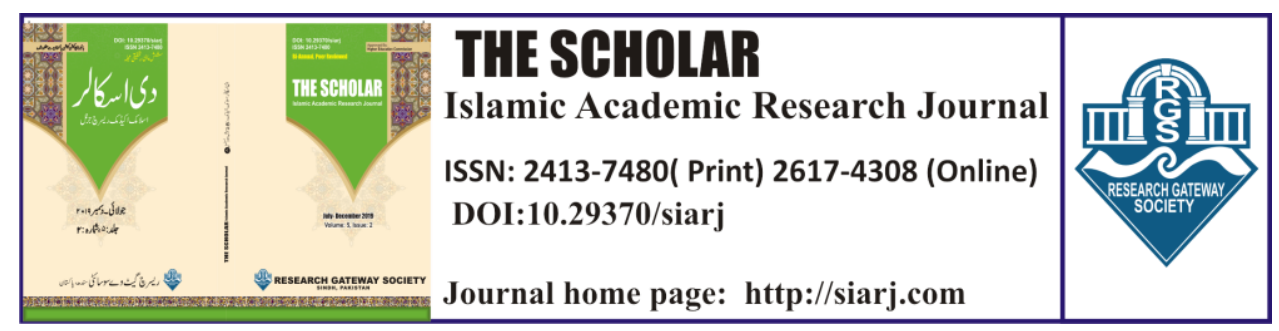

$$
\text { تأثير القرآن الكريم في شعر أمير مينائي }
$$

\title{
INFLUENCE OF HOLY QURAN IN THE POETRY OF AMEER MEENAI
}

\section{1- Nasir Husain}

Research Scholar, Dept. Of Arabic, Bahauddin

Zakariya University, Multan.

Email : ramzanmadni786@gmail.com

ORCID ID:

\section{https://orcid.org/0000-0001-5507-0979}

To cite this article:

Husain, Nasir, and Muhammad Shafqatullah. "INFLUENCE OF HOLY QURAN IN

THE POETRY OF AMEER MEENAI" The Scholar-Islamic Academic Research Journal 5, No. 2 (December 16, 2019): 34-59

To link to this article: https://doi.org/10.29370/siarj/issue9ar2

Journal

Publisher

DOI:

URL:

License:

Journal homepage

Published online:
The Scholar Islamic Academic Research Journal Vol. 5, No. 2 ||July-December 2019 || P. 34-59 Research Gateway Society 10.29370/siarj/issue9ar6 https://doi.org/10.29370/siarj/issue9ar6 Copyright c 2017 NC-SA 4.0 www.siarj.com 2019-12-16 


\title{
تأثير القرآن الكريم في شعر أمير مينائي \\ INFLUENCE OF HOLY QURAN IN THE POETRY OF AMEER MEENAI IH-UL-ISLAMI AND PAKISTANI LAW
}

\author{
Nasir Husain, Muhammad Shafqatullah
}

\begin{abstract}
:
Al-Madih Al-Nabavi is a popular Islamic poetry composition among the Muslim poets because the prophet Muhammad (PBUH) is beloved personality of all Muslims and the respectable to be followed in every movement of life. The poets in every era of Islamic History said their poetry verses in the praise of Prophet Muhammad (PBUH) in the subjective means including the various topics of Al-Madih Al-Nabavi. The poets of other nations like Persian and Urdu nations started expressing their emotions and sentiments of love to the Prophet Muhammad (PBUH). Ameer Meenai was a great poet of Urdu literature in sub-continent. He was born in Lucknow, India in 1826. He started poetry in his early age. His chapter on Eulogistic Poetry has great fame and published in 1916 with the title of "Mahamid Khatam-ul-Nabiyyeen (PBUH)". He was impressed by teachings of the Holy Quran. In this article, we will discuss the impact of the Holy Quran in his poetry. This is very important topic of research in literature, especially in Muslim Literature in the world. With the hope that this work will be beneficial for the further researches and for the new scholars as well. This article, basically, focuses upon poetical works of Ameer Meenai, especially on "Mahamid Khatam-ul-Nabiyyeen (PBUH)" and highlights the topics of Holy Quran, its causes and effects of teachings of Holy Quran on his poetry. To find out the results in this field, this research comparatively analyzed the poetical works of Ameer Meenai. After conducting the study of his poetical works, the researcher came to know that there is a remarkable impact of Holy Quran on the poetry of Ameer Meenai. For example, he was interested in miracles and Seerat-ulNabi (PBUH) among the other topics of Holy Quran. Similarly, in his Eulogistic poetry there is explanation and justifications of Quranic topics. However, finest of his works are those in which he used, word by word, Quranic verses in his poetry composition that shows distinctions of both languages and highlights the limitations of poetry and prose.
\end{abstract}


KEYWORDS: Quran, Ameer Meenai Al-Madih Al-Nabavia, Eulogistic Poetry, Sub-continent, Muslim poets, Urdu, Persian.

الكلمات المفتاحية: تأثير، القرآن ، شعر ، أمير مينائي ، الشعراء المتأخرين، شبه القارة الهندية

$$
\begin{aligned}
& \text { والباكستانية } \\
& \text { الملدخل: }
\end{aligned}
$$

إن أمير مينائي يُعَدِّ من الشعراء المتأخرين الكبار من أرض لكنؤ في شبه القارة والهند حالياً. ولكن لاتوجد ترجمة حياته المبسوطة بعد التتبع لايسهل النقد عليه، ولايمكن التعليق على أعماله بصفة كاملة ولكن سوف نحاول على عرض قدر كافٍ لترجمة وخصائص شعره. وهذا السبب شهرته الزائفة بين الأوساط العلمية والأدبية والأكاديمية حتى لانجد دواوينه بشكل كامل لكي تتمّ دراستها نقدية أو تحليلية أو يتمّ عرضها إلى حلقات العلم. وبالأخصّ على شعره في المديح النبوي صلي الله عليه وسلم.

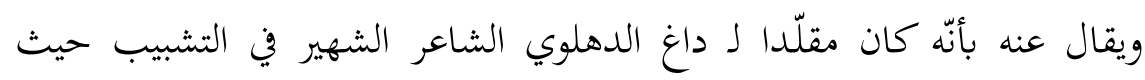
يقول كريم أحمد عن هذا: "إن أكبر جزء عن حياة أمير هو في طي الخفاء، وترجمة حياته قبل سنة 1857م

$$
\begin{aligned}
& \text { مفقودة مثل رصيده الشعري."1 } \\
& \text { ترجمة حياته: }
\end{aligned}
$$

*Research Scholar, Deptt. Of Arabic, Bahauddin Zakariya University, Multan \& SS (Subject Specialist in Arabic) in GHSS. 135/10R, Jahanian, Khanewal.

**Prof. of Arabic \& Dean Faculty of Languages and Literature, Bahauddin Zakariya University Multan.

${ }^{1}$. Kareem -ud- Deen Ahmad, Ameer Meenai Aor Un k Talaamiza (Lahore: Aaena e Adab, 1982), 11. 
كان أمير مينائي ينتمي إلى عائلة كريمة معروفة باسم "مينائي" في شبه القارة الهندية والباكستانية. ولهذه الأسرة مكانة مرموقة في الزهد والتقوى،والفيض المعنوي والعلم والعمل في عامة الناس وخاصته.

وعلاوةً عن ذلك كان والده المولوي كرم أحمد مينائي شخصية روحانية، وله علاقة

قوية بأهل الشرف، وبرع في العلوم بجهاتما العديدة وكان من أبرز كتّاب لكنؤ بأرضها. وكان يصل نسبه إلى شاه مينا رحمه الله.

$$
\text { وكتب الدكتور أبو الليث الصديقي عن شاه مينا: }
$$

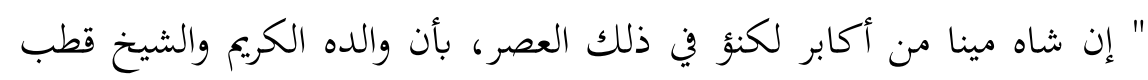
الدين قد وردا في أرض لكنؤ في القرن التاسع الهجري. ثم وُلد شاه مينا رحه الله في هذه المدينة. وكانت انقرضت له القطعة الأرضية هبة له من قصر الدهلي التي بقيت في تصرفه إلى عصر برهان الملك النواب سعادت خان، ولكن استولى عليها الحكومة في عهد النواب

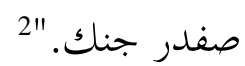
وكان أمير مينائي قد بايع على يد أمير شاه في طريقة الجشتية الصابرية، وقد سجّل كريم أحمد عن هذا:

"ولد أميرأحمد أمير مينائي 16من شعبان سنة 1244هـ الموافق 21 فبرائر سنة 1826م يوم السبت وقت 10:30صباحاً في لكنؤ. وكان ولداً صغيراً لمولوي كرم تُحَّت

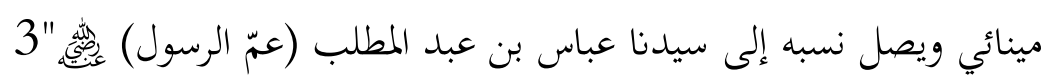
وقد اختلف المؤرخون في سنة ولادته، يقول الدكتور رفيع الدين إشفاق عن هذا:

2. Dr. Abul Layth Siddiqui, Lucknow Ka Dabistan e Shayari (Lahore: Urdu Markaz, 1965), 234.

3. Ahmad, Ameer Meenai Aor Un k Talaamiza, 14-15. 


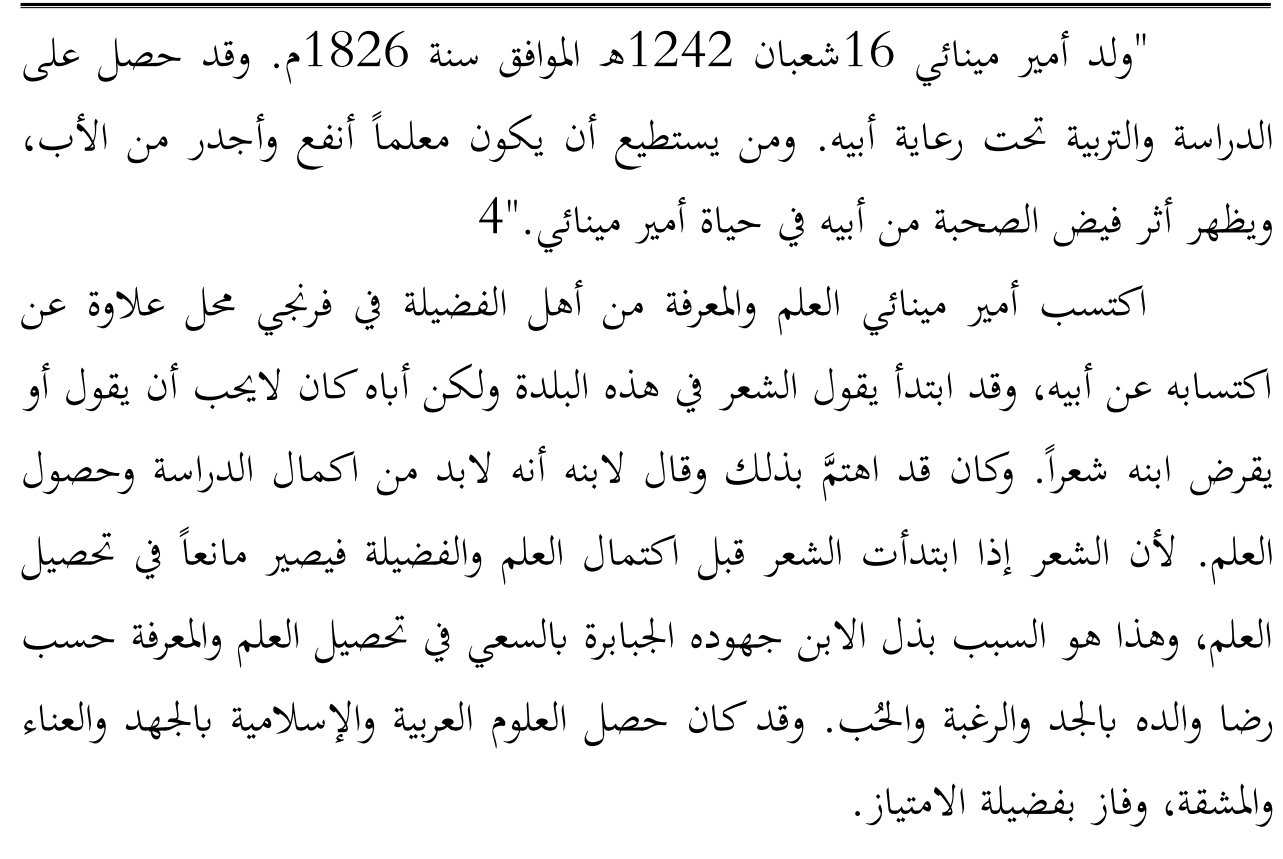
وعندما ارتحل أبوه إلى مولاه الكريم من هذه الدنيا إلى دار الآخرة،وعندئذٍ كانت

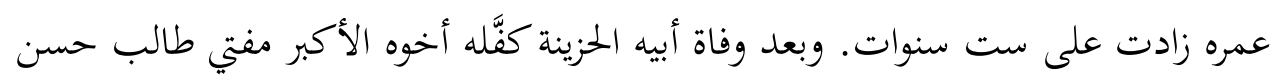
واهتََّّ بدراسته وتربيته.

كان ابتدأ دراسته بقراءة القرآن ودرس الكتب المتداولة المختصرة على يد مولوي ظفرعلي وريهنوي، وعلاوة عن ذلك أخوه المتوسط حافظ عنايت علي الذي كان بدأه بتدريس اللغة العربية. كما يقول كريم أحمد عن هذا الصدد:

"وعند وفاة أبيه كان عمره زادت على ست سنوات فكفَّله أخوه الأكبر مفتي

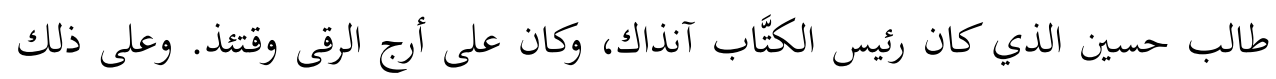
كفَّله مثل الوالد لابنه. فقد قرأ أمير مينائي القرآن الكريم والكتب المختصرة المتداولة في

4. Sayyid Rafee -ud- Deen Ishfaq, Urdu Mein Naatiya Shayari, First (Karachi: Urdu Academy, 1976), 282. 
تأثير القرآن الكريم في شعر أمير مينائي

المدارس الدينية على يد مولوي ظفرعلي وريهنوي. كان أخوه المتوسط ابتدأه بدراسة اللغة العربية الذي كان تبوّاً مقامه للتدريس والافتاء من آبائه. "5 لمولئ قد حصل أمير مينائي درجة الامتياز والفضيلة في التعليم والتربية فاقتضى الفطرة أن يرعاه معلّماً الذي كان يُرشده في الشعر وهو موافقاً لذوقه، فهو سعيد بأن يتلمَّذ تحت رعاية مظفرعلي خان. وعندما بلغ ستة عشر سنة من عمره بدأ بتحصيل المنطق والفلسفة على يد المفتي يُمَّمَ سعدالله المرادآبادي، وقرأ الأدب على يد المولوي تراب على اللكهنوي. وكان ينتمي إلى أسرة دينية عريقة وفي طبيعته الزهد والسلوك القويم، والخصائل

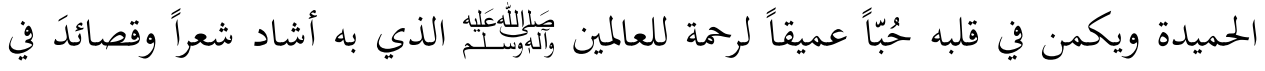
مدحه بعد زيارة ولقاءات بشاعر مادح كبير محسن كاكوري. وأثناء حرب الحرية سنة 1857م اضطرَّ أمير مينائي إلى ترك لكنؤ مع الأفاضل الآخرين ووصل إلى كاكور وهناك لقي مع محسن كاكوري الشاعر الشهير آنذاك في المديح النبوي.

$$
\text { ويقول د. رفيع الدين إشفاق عن هذا اللقاء: }
$$

" إن وجوده في كاكور كان حدثاً عظيماً في حياته بأن محسن الكاكوري هو الذي

حثَّه على إشادة الشعر في المديح النبوي، وهذا هو السبب الأساسي في هذا الصدد."6 حتى قال أمير مينائي عن أرض كاكوري، تضميناً له حيث قال محسن كاكوري:

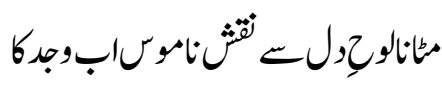

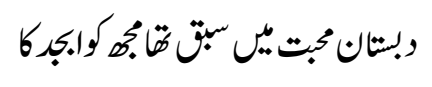

$$
\begin{aligned}
& \text { (أن أحو كلَّ شيئ عن لوح قلبي وهذا كان هو الدرس الأوّل لكي أدخل من باب الحُبّ). } \\
& \text { فقال أمير مينائي مشطِّرً على هذا البيت: }
\end{aligned}
$$

5. Ahmad, Ameer Meenai Aor Un k Talaamiza, 16.

${ }^{6}$. Ishfaq, Urdu Mein Naatiya Shayari, 282. 
تأثير القرآن الكريم في شعر أمير مينائي

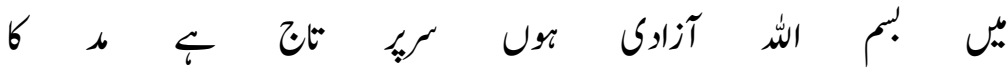

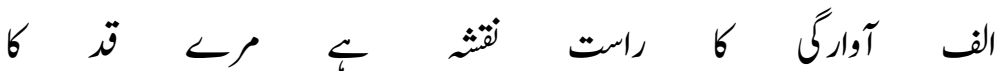

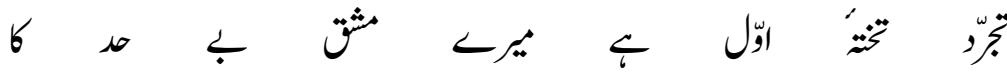

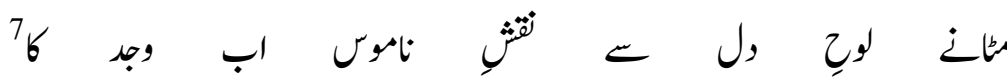

(أنا الحُرُ على رأسي تاج المدّ وأبتوّل هكذا، وهذه طبعيتي. وأبترّد عن كل أعمالي

$$
\text { لكي أحو كلّ شيع عن لوح قلبي). }
$$

وهو كان مجبولاً في قرض الشعر ونظمه وكان يقول عن التوكل والعجز والزهد والتصوف، وكان يحمل خلفية دينية التي تؤدي به إلى نظم المديح النبوي كما يقول عنه د.

$$
\text { رياض بجيد: }
$$

" إنه كان يقول شعراً عن المديح النبوي أحياناً ولكنه اتخذ هذا الصنف الأدبي كفنٍّ بعد لقاهه مع محسن كاكوري بكاكوري ونجد تأثراً بالغاً في إشادة أمير مينائي المديح

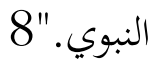

وألف الدواوين الكثيرة في الشعر مثل محامد خاتم النبيين، ونعتيه مسدّس (تسديس المديح النبوي)، وشامِ أبد (الليلة الخالدة)، وليلة القدر،و شاه أنبياء (ملك الرسل). وله ثلاث قصائد في المديح النبوي مثل محامد خاتم النبيين، وخيابانِ آفرينش (بستان الكون) الذي يحتوي فيه شعر المديح ويتعلق بالمولد النبوي. وهو ينظّم أبياتاً عديدة غير الدواوين في المديح النبوي في مجموعات مختلفة.

أصبح أمير مينائي في أواخر عمره مريضاً ومصابا بالآلام المتنوعة، ولزم بالفراش لشهر كامل حتى أن توفي 19جمادى الآخر سنة 1318هـ بمطابق بالسنة الميلادية

7. Ishfaq, Urdu Mein Naatiya Shayari, 282.

${ }^{8}$. Dr. Riaz Majeed, Urdu Mein Naatgoi, First (Faisalabad, 1992), 348. 
تأثير القرآن الكريم في شعر أمير مينائي

1900 في حيدرآباد دكن. وكان هذا صادماً لأهله ولأصحابه كلّهم، فقال مرزا داغ على موته في حالة الاضطراب:

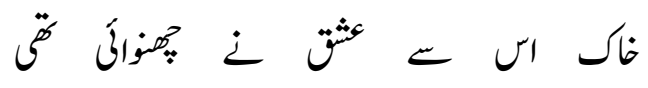

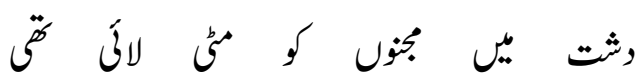

(هو كان سالكاً طريق العشق وكان وريث المجنون بتجواله في الصحراوات) مكانته في المديح النبوي:

قد ساهم أمير مينائي في تطوير فنّ المديح النبوي على غرار الشاعر الشهير محسن كاكوري في شبه القارة الهندية الباكستانية، وهو حاول أن ينظم شعره في هذا الصنف الأدبي بصدق مشاعرة و صحة أحداث الموضوع كما هو يكتب في كتابه عن المولد النبوي بعد كتابة المنظومات في المديح النبوي: "قصدتُ أن أكتب عن المولد النبوي وأهتم بصحة الروايات في أحداث المولد النبوي."

وهو يكتب في المديح النبوي ومنظوماته ينشدها كثير من المنشدين في مناسبات

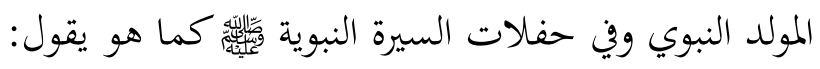

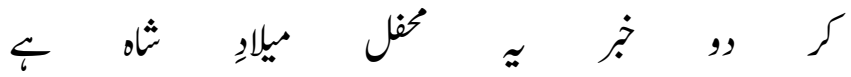

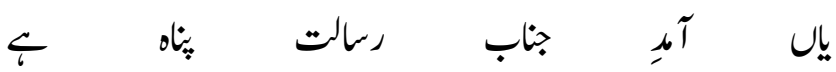

أمت

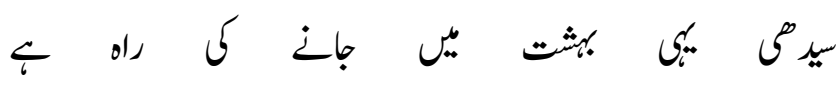

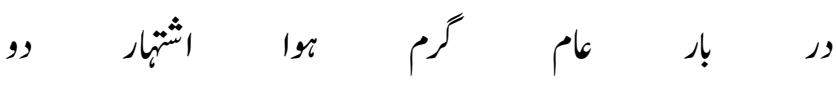

${ }^{9}$. Majeed, Urdu Mein Naatgoi, 349. 
تأثير القرآن الكريم في شعر أمير مينائي

$$
\text { 3- سرمه بصيرت (كحل البصيرة): }
$$

قد صحّح فيه الكلمات الخاطئة الشائعة بين الناس ونقحها.

$$
\text { 4-همارِ هند (ربيع الهند): }
$$

قد جمع فيه المصطلحات الأردية وأمثالها.

5-نورِ بتلّى ابركرم ( سحاب الكرم وبتلّي النور):

يشتمل على قصص وحكايات أخلاقية.

$$
\text { 6-ذكر شاه انبياء (ذكر سيد الأنبياء): }
$$

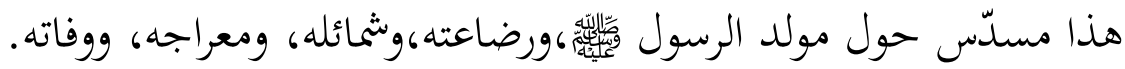

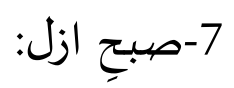

منظومة في ذكر مولد الرسول

$$
\begin{aligned}
& \text { 8-شامِ ابد ( ليلة سرمدي): قد ذكر فيه وفاة الرسول الكريم. } \\
& \text { 9-مضامين دل آشوب (الموضوعات تقلق القلب): } \\
& \text { هذه منظومة لأمير مينائي. }
\end{aligned}
$$

$$
\text { 10- ليلة القدر: }
$$

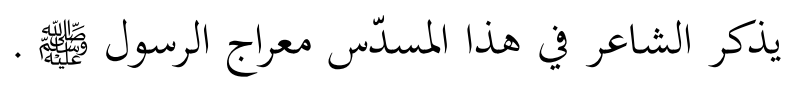

11- بجموعة واسوخت: قد صنَّف مع المجموعات الستة الأخرى التاريخية سنة

$$
\text { 1284 }
$$

12 - - - محامد خاتم النبيين: 


$$
\begin{aligned}
& \text { تأثير القرآن الكريم في شعر أمير مينائي }
\end{aligned}
$$

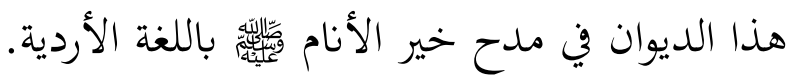

$$
\begin{aligned}
& \text { 13- انتخابِ يادكار (نخبة الذكريات): } \\
& \text { يذكر فيه تراجم شعراء رامبور. } \\
& \text { 14- نماز كـ اسرار (الصلوة): } \\
& \text { ذكر فيه أدعية الصلاة. }
\end{aligned}
$$

\section{تأثره بالقرآن الكريم في المديح النبوي}

إن القرآن له أثر بارز في حياة أمير مينائي، وهي حقيقة اعترف المي بها جميع من كتب عنه، وإنه ولد في أسرة دينية وتربّى على الأفكار الطيبة والخصائل الحميدة. ويقول أمير مينائي شعراً معبِرًاً مفهوم هذه الآية الكريمة: 
تأثير القرآن الكريم في شعر أمير مينائي

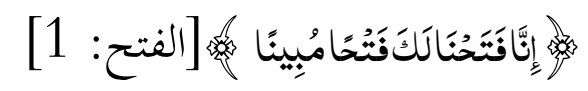

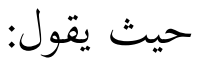

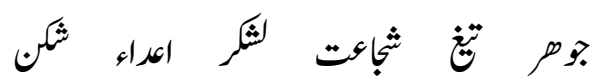

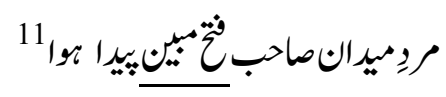

(قد ولد من كان له حماسة وجيوش فاتحة ولايتزلز قدمه في المعارك ووعد الله له

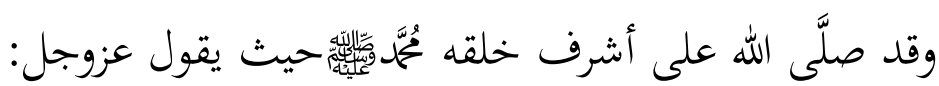

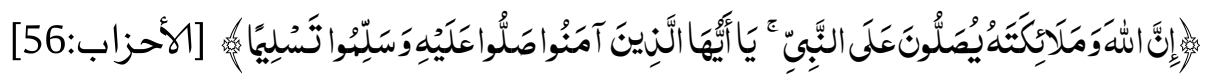
يقول أمير مينائي:

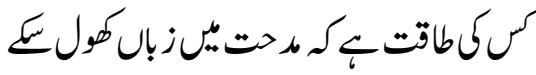

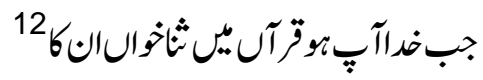

(ومن يستطيع أن يمدح رسول الاسلام لما يصلّي عليه

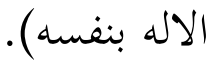

${ }^{11}$. Meenai, Mahaamid -e- Khatam -Un- Nabiyyeen, 349.

${ }^{12}$. Meenai, 31 . 


ويقول أيضاً:

(كيف لأحد أن يمدح أحمد فيّالَّه، و الله يصلّي عليه؟ وكل الكون تحت قدمه مثل نعله). ويقول أيضاً:

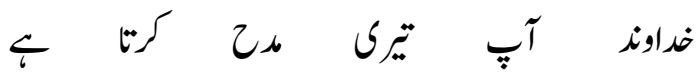

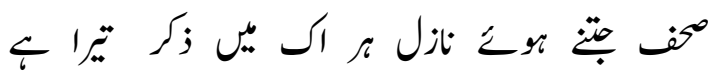

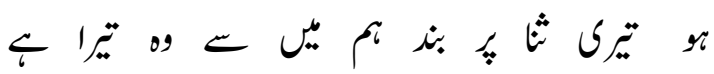

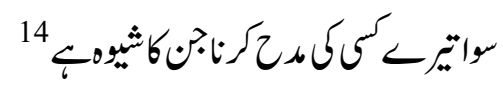

( إن الله يثني عليك وكل الصحف مليئة بذكرك ونحن لانمدح غيرك يارسول الله.)

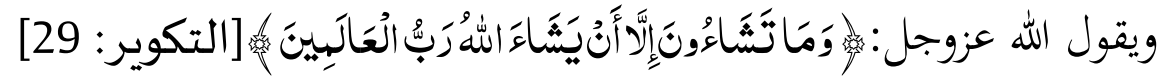

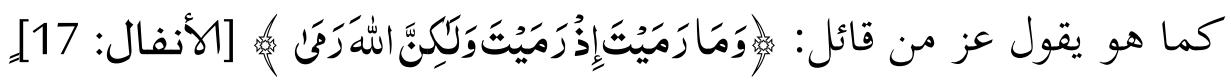
فيقول أمير مينائي وهو يذكر هذه المعاني الجليلة:

${ }^{13}$. Meenai, 131.

${ }^{14}$. Meenai, 132. 


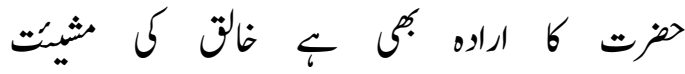

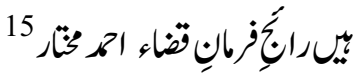

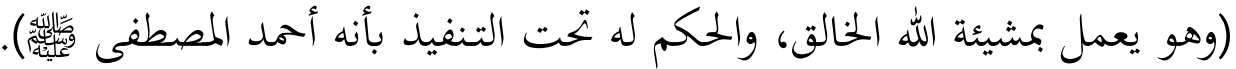

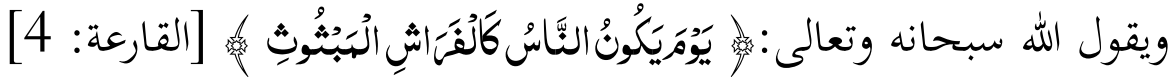

$$
\begin{aligned}
& \text { ويعبّر أمير مينائي هذا المفهوم: }
\end{aligned}
$$

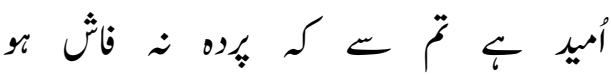

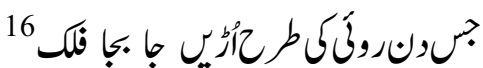

(نرجو منك أن لاتفضحنا بافشاء أسرارنا يوم تكون الآفاق كالعهن المنفوش).

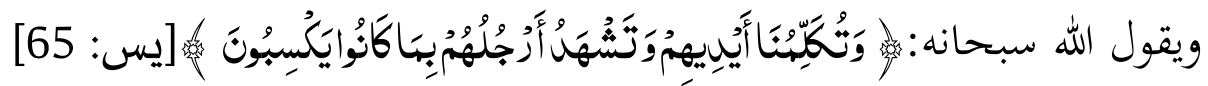
يقول أمير مينائي:

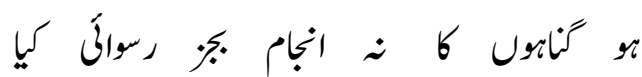

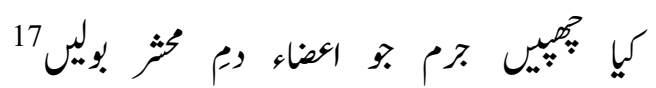

( وهذه فضيحة كبرى لما تشهد أعضاء الجسم عن الجرائم والذنوب).

ويقول الله عزوجل:

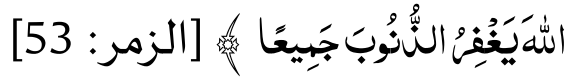

15 . Meenai, 149.

${ }^{16}$. Meenai, 60 .

${ }^{17}$. Meenai, 70 . 


$$
\begin{aligned}
& \text { يقول أمير مينائي: }
\end{aligned}
$$

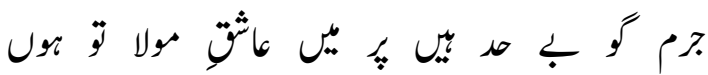

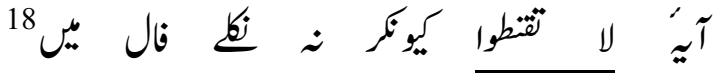

(وإن كنتُ قد أذنبت كثيراً ولكني أحب الرسول فكيف لاتخرج الاستخارة باسمي في القرآن آية لاتقنطوا من رحمة الله؟)

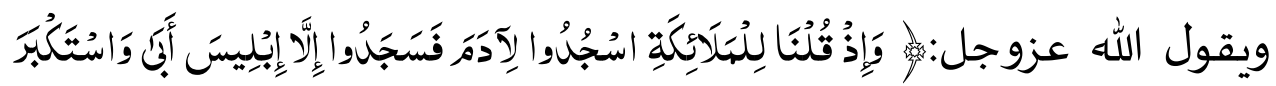

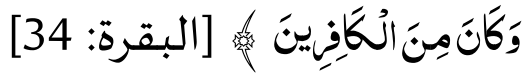
يقول أمير مينائي:

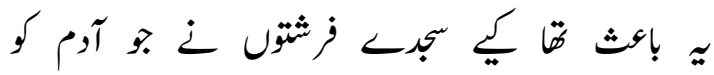
كم انع ملب: 19

(وهذا كان هو السبب بأن الملائكة قد سجدوا لآدم عليه السلام بأفم رأوا في

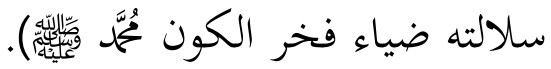

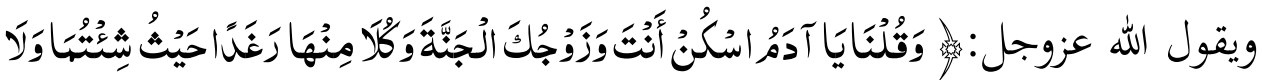

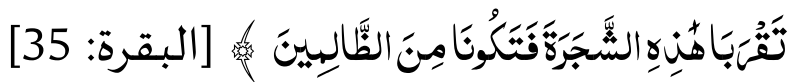
يقول أمير مينائي:

\footnotetext{
${ }^{18}$. Meenai, 60.

${ }^{19}$. Meenai, 73.
} 


$$
\begin{aligned}
& \text { اكر اس خاك ع عاسن كا لوسم وه بهل } \\
& \text { ن نوظق كما ع كنم اصتيانِ عزد آرم كو20 }
\end{aligned}
$$

$$
\text { (لوكان آدم أخذ الحنطة قبل ذلك فليس له حاجة إلى الاعتذار) }
$$

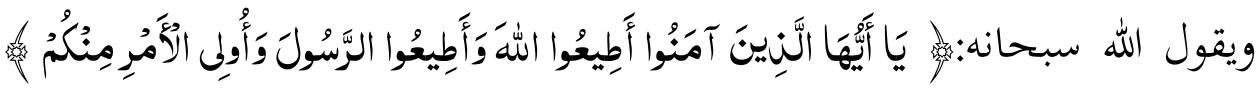

[النساء: 59]

$$
\text { يقول أمير مينائي: }
$$

$$
\begin{aligned}
& \text { طاوتِ }
\end{aligned}
$$

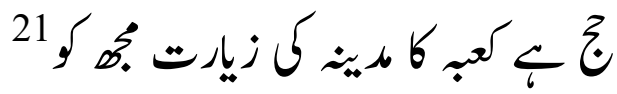

(إن طاعة الرسول هي طاعة الله، ولما أزور المدينة المنورة يعتبر هذا هو الحج بيت

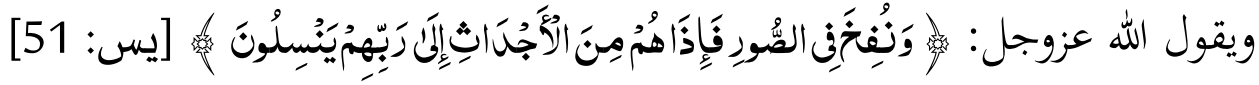

$$
\text { يقول أمير مينائي: }
$$

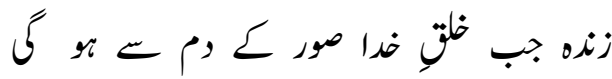

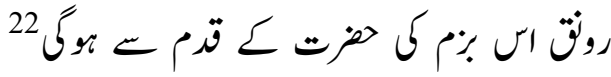

\footnotetext{
${ }^{20}$. Meenai, 72.

${ }^{21}$. Meenai 74.
} 
(لما نفخ في الصور ويقوم الناس من مرقدهم سوف ينوّر رسول الله هذه الحفلة).

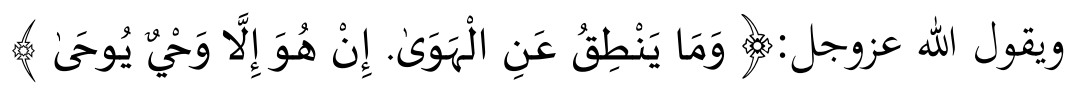

$$
\text { يقول أمير مينائي: }
$$

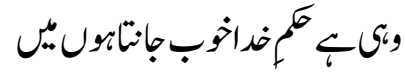

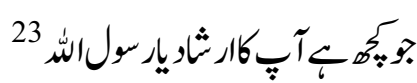

(يارسول الله، أنا أعرف أن قولك هو حكم الله في الحقيقة).

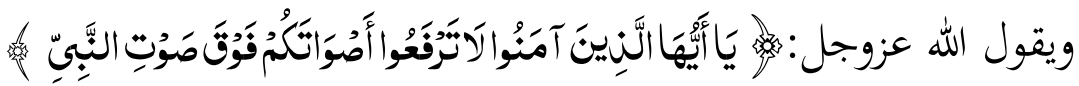

[الحجرات: 20 يقول أمير مينائي:

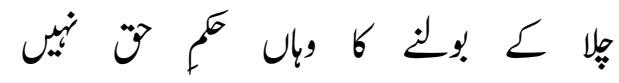
كأولن

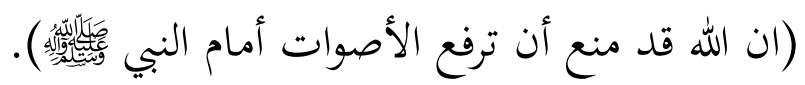

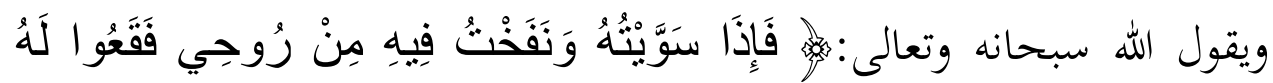

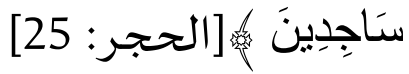
يقول أمير مينائي:

22 . Meenai, 79.

23 . Meenai, 82.

${ }^{24}$. Meenai, 85 . 


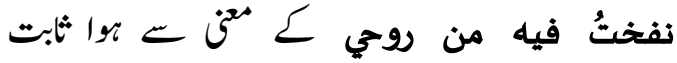

$$
\begin{aligned}
& \text { زنان }
\end{aligned}
$$

(قد ثبت بالآية الكريمة نفختُ فيه من روحي بأن هناك خزائن كامنة في هذا

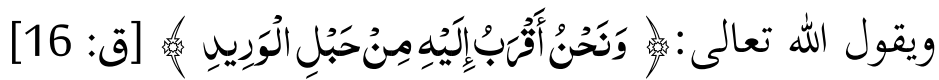

$$
\text { يقول أمير مينائي: }
$$

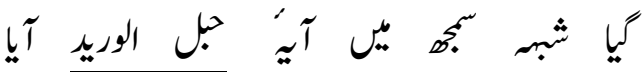

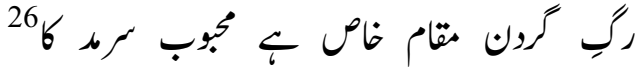

(فهمت معنى الآية الكريمة نحن أقرب من حبل الوريد بأن الله يسكن عند حبل

ويقول الله سبحانه :

$$
\begin{aligned}
& \text { يقول أمير مينائي: }
\end{aligned}
$$

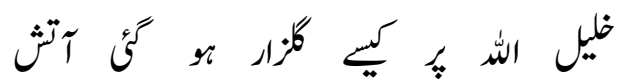

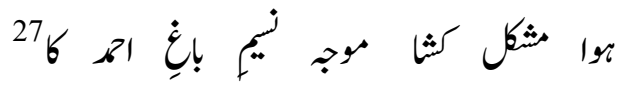

\footnotetext{
25 . Meenai, 5.

26 . Meenai, 5.

27 . Meenai, 6.
} 
( قد جعل الله النار برداً لخليله ابراهيم عليه السلام، وهكذا حلَّت مشاكل وجاء

$$
\text { ريح بستان أحمد الأخضر. (لن الن بردان }
$$

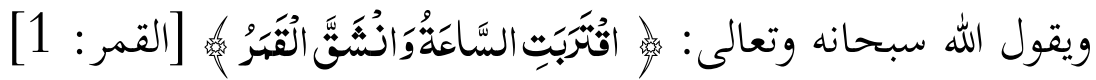

$$
\begin{aligned}
& \text { ويقول أمير مينائي: }
\end{aligned}
$$

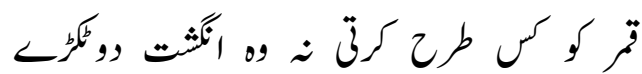

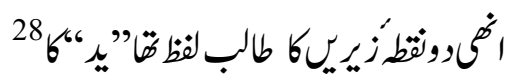

(وكيف لاتنشق القمر بأصبعه الذي به كان رسول الله

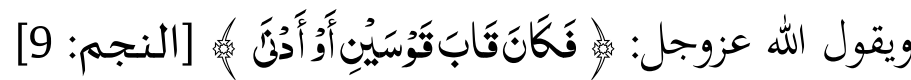

$$
\text { ويقول أمير مينائي: }
$$

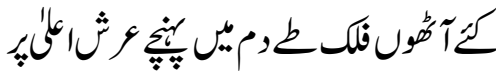

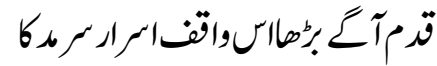

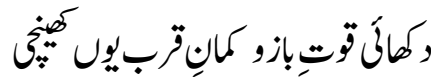

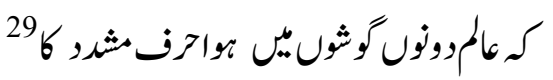

(قد أسرى الى العرش المعلّى هو عالم الأسرار وقد أظهر سطوته وقربه اليه حتى

$$
\text { تغغلَّب على الكون). }
$$

${ }_{29}^{28}$. Meenai, 9.

29. Meenai, 10. 


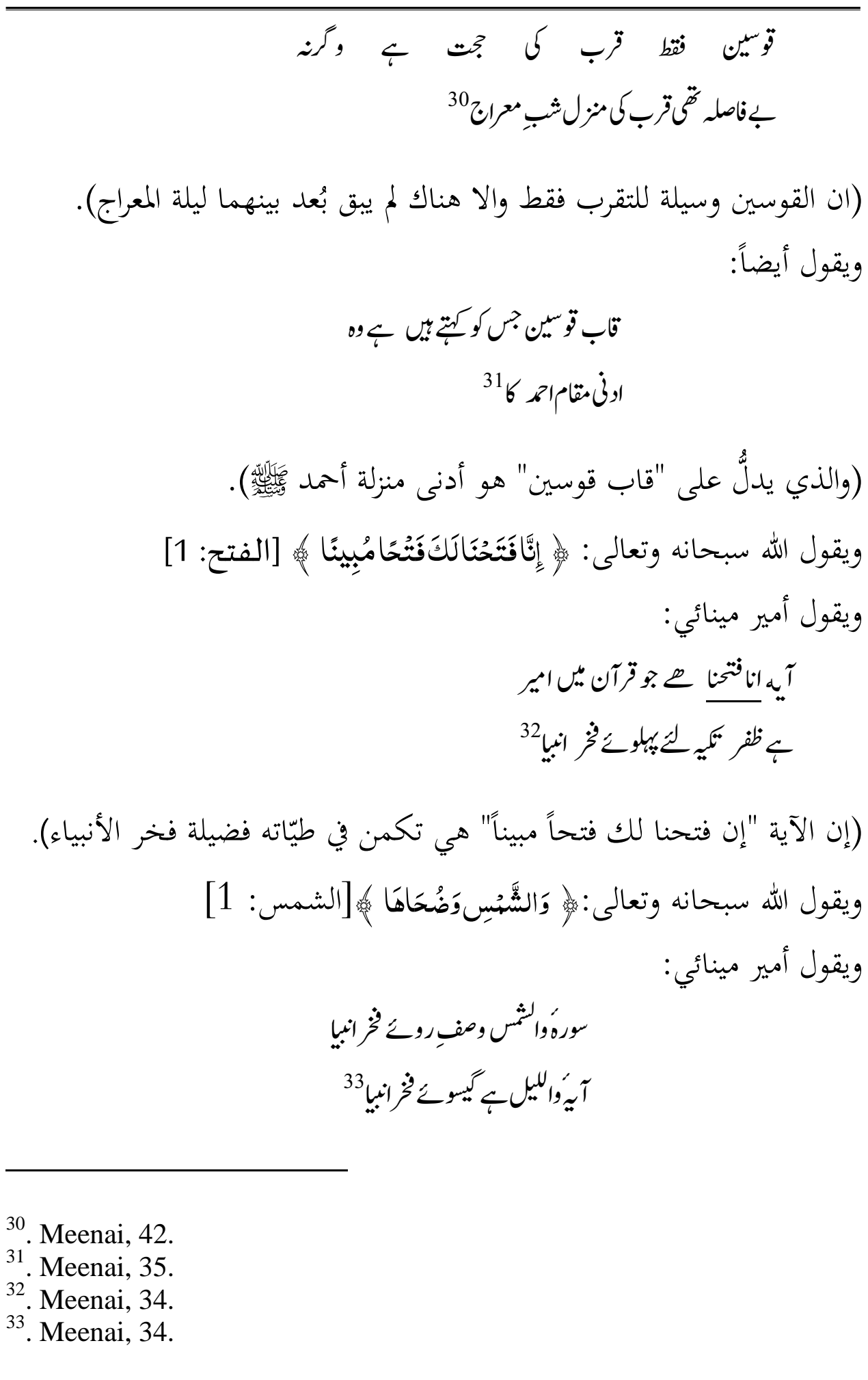


(ان سورة الشمس في بيان وصف وجهك المنير وسورة الليل هي بيان شعرك

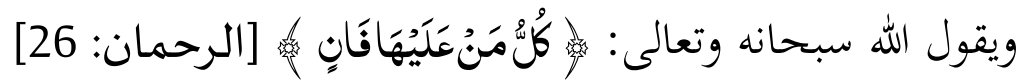
ويقول أمير مينائي:

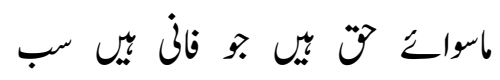

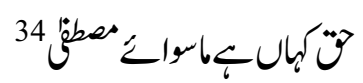

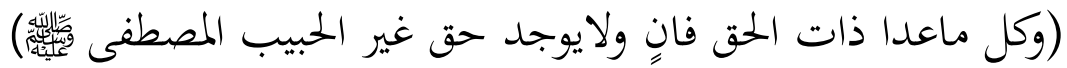

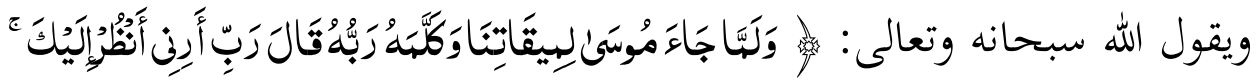

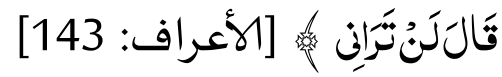
ويقول أمير مينائي:

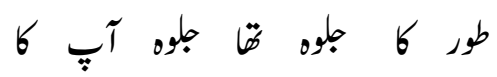

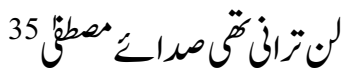

(فإن تجلّي الطور كان ظهورك، وصوت " لن تراني" كان نداءك).

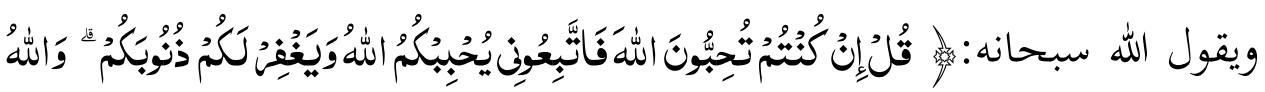

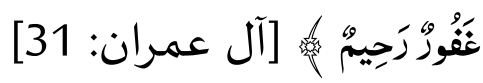
يقول أمير مينائي:

${ }_{35}^{34}$. Meenai, 36.

35. Meenai, 37. 


$$
\begin{aligned}
& \text { وه بات كر كم رضا مند ،ول رسول كريم }
\end{aligned}
$$

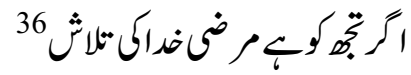

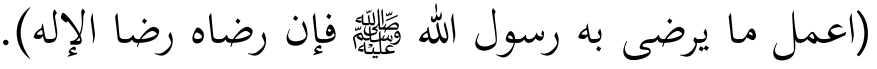

$$
\begin{aligned}
& \text { ويقول أمير مينائي: }
\end{aligned}
$$

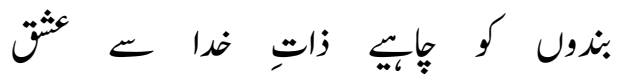

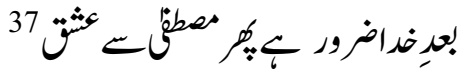

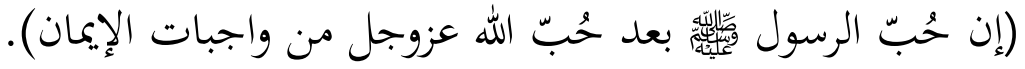

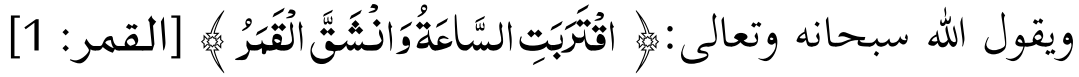

$$
\begin{aligned}
& \text { يقول أمير مينائي: }
\end{aligned}
$$

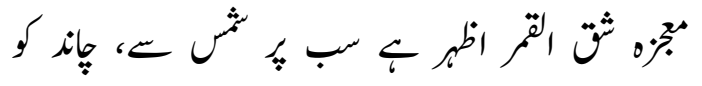

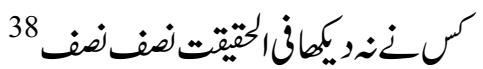

(معجزة شقّ من آيات الله عزوجل ، وقد ظهر جلياً بأن كلهم رأوا القمر نصفاً).

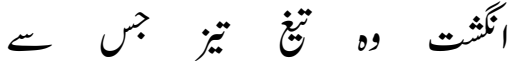

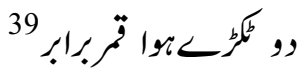

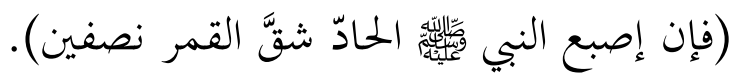

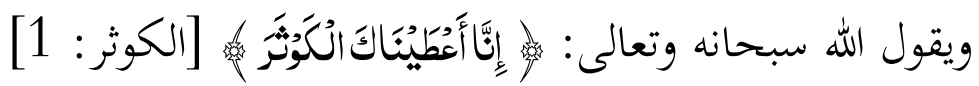

\footnotetext{
${ }^{36}$. Meenai, 54.

37 . Meenai, 59.

${ }^{38}$. Meenai, 58.

39 . Meenai, 114.
} 


$$
\begin{aligned}
& \text { يقول أمير مينائي: } \\
& \text { حث }
\end{aligned}
$$

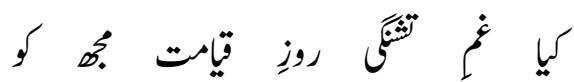

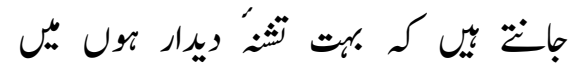

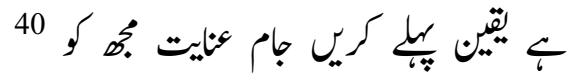

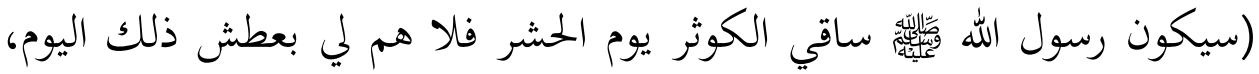
فإني أقول له: أنا كنتُ أتنمنّى لرؤيتك منذ مدّة طويلة فأعطني كأساً من كرمك). ويقول الله سبحانه وتعالى:

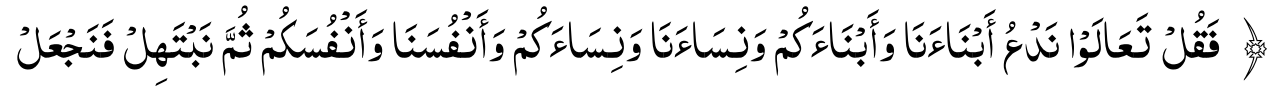

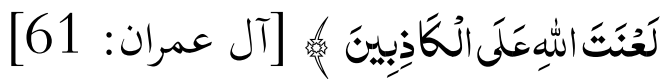

$$
\begin{aligned}
& \text { يقول أمير مينائي: } \\
& \text { مبإلب }
\end{aligned}
$$

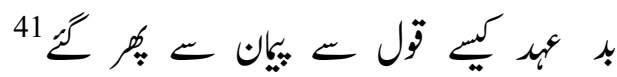

(فالله يدعوهم إلى المباهلة ولكن لم يأتوا وعجزوا أن يقوموا أمام البراهين الساطعة). ويقول الله سبحانه وتعالى:

${ }_{41}^{40}$. Meenai, 75 .

${ }^{41}$. Meenai, 88. 


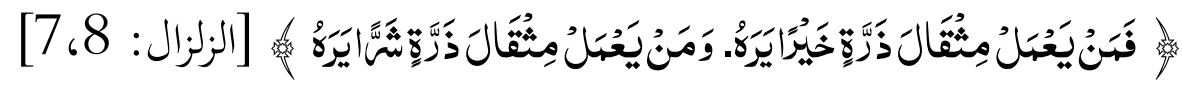

$$
\begin{aligned}
& \text { يقول أمير مينائي: }
\end{aligned}
$$

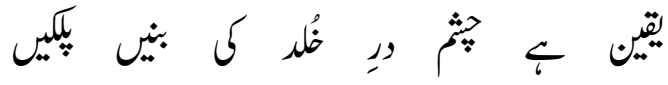

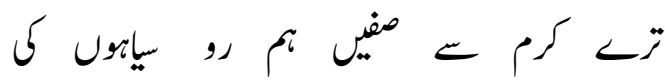

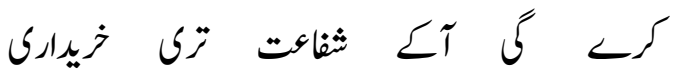

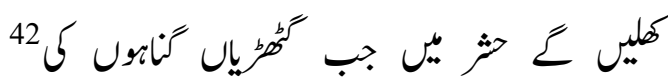

$$
\begin{aligned}
& \text { (نحن نتمنّى كرمك يوم تُكشف الذنوب والمعاصي، ونستشفع بك). }
\end{aligned}
$$

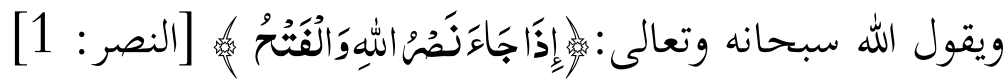

$$
\begin{aligned}
& \text { يقول أمير مينائي: }
\end{aligned}
$$

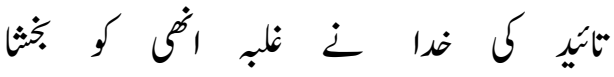

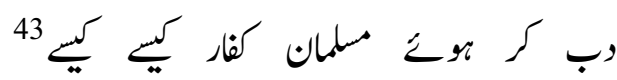

(قد فتح الله له وتغلّب حتى أسلم الكفار بعد سطوته الغالبة).

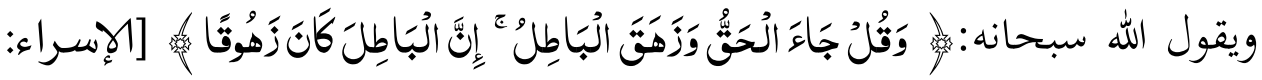

${ }_{43}^{42}$. Meenai, 89-90.

43. Meenai, 90. 


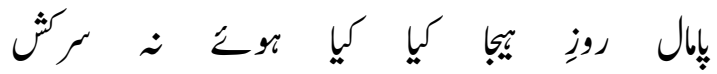

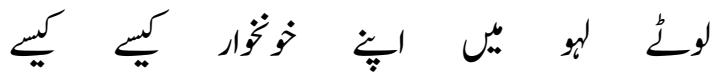

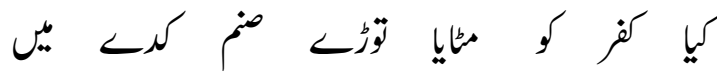

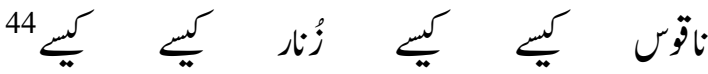

(قد فضح الله أهل الأهواء والأباطيل بنوره وحقه الذي جاء به سيدنا رسول الله).

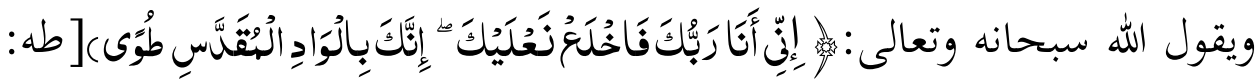

$$
\begin{aligned}
& \text { هت اون }
\end{aligned}
$$

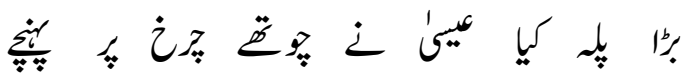

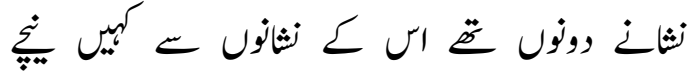

$$
\begin{aligned}
& \text { بوفتونوكِيازوركمانوارِنوتِ } 45
\end{aligned}
$$

(قد وصل موسى إلى الطور وصعد عيسى إلى السماء الرابعة، ولكن سيدنا تُمَّا عليه الصلاة والسلام هو الرامي الوحيد الذي بلغت سهامه المرمية إلى المدف

\footnotetext{
44 . Meenai, 90.

45. Meenai, 122.
} 


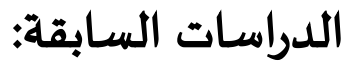

ومن المعلوم أن موضوع المدائح النبوية موضوع هام لا في الأدب العربي فحسب بل في أداب اللغات المتداولةالأخرى لدى المسلمين على بسيطة الأرض فبذل شعراء الأردية في شبه القارة الهنديةالباكستانيه جهودهم في المدائح النبوىة وجاءوا بالروائع فيها وامتاز منهم أميرمينائي وألطاف حسين حالي و العلامة مُحَّم اقبال وظفر علي خان. فاتخذ الباحثون شعرهم الأردي موضوعاً لبحوثهم على درجة ماجستير الفلسفة والدكتوراة وقارن بعض الباحثين بين هؤلاء الشعراء في المدائح النبوية وبشعر كبار شعراء العربية فمن هؤلاء الباحثين الأستاذة الدكتوراة صائمةالصديقي التي قارنت بين شعر أحمد شوقي و مُحَّة اقبال في رسالتها لماجستير فلسفة اللغة العربية ، وكذلك قام يُمَّمَ كاظم بمقارنة بين شعر المادح النبوي عبدالرحيم البرعي وظفر علي خان في رسالته للدكتوراة.

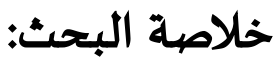
وفي الختام نستطيع أن نقول على بصيرة أن الشاعر الأردي الشهير ”أمير مينائي ، قد نال الحظ الكبير من التراث اللغوي الأردي الذي يستفيد من اللغة العربية استفادة البنت من الأم. وكما هو معلوم أن القرآن الكريم هو المتن الأشهر والأكثر تداولاً من جميع الكتب العربية، فلذلك نرى ههنا أنَّ لأسلوب القرآن الكريم أثر واضح جلي على شعر أمير مينائي، يستشهد بذلك الأثر ويسمع دوي ذاك في شعر أمير مينائي كلٌٌ من يتفحص في شعره ويقرأه قراءة هادفة هادئة. وربما كان لهذا الأثر سبب آخر، وهو مواضيع شعر أمير مينائي، التي 


$$
\begin{aligned}
& \text { يرجع أكثرها إلى المديح النبوي أو -ما نستطيع أن نسمّي باصطلاح أشمل - إلى } \\
& \text { "الأدب الديني"، والعلاقة بين هذا النوع من المواضيع الأدبية وبين القرآن الكريم } \\
& \text { أوضح من أن يورد لها أمثال وشواهد. }
\end{aligned}
$$

